\title{
The role of KIR genes and ligands in leukemia surveillance
}

\author{
Florian Babor $^{1}$ *, Johannes C. Fischer ${ }^{2}$ and Markus Uhrberg ${ }^{2}$ \\ ' Department of Pediatric Oncology, Hematology and Clinical Immunology, Center for Child and Adolescent Health, \\ Heinrich Heine University, Düsseldorf, Germany \\ ${ }^{2}$ Institute for Transplantation Diagnostics and Cell Therapeutics, Heinrich Heine University, Düsseldorf, Germany
}

\section{Edited by:}

Eric Vivier, Centre d'Immunologie de Marseille-Luminy, France

\section{Reviewed by:}

Stephen K. Anderson, National Cancer Institute-Frederick, USA Karl-Johan Malmberg, Oslo University Hospital, Norway

\section{*Correspondence:}

Florian Babor, Department of Pediatric Oncology, Hematology and Clinical Immunology, Center for Child and Adolescent Health, Heinrich Heine University, Moorenstrasse 5, Düsseldorf 40225, Germany. e-mail: florian.babor@med. uni-duesseldorf.de
The antileukemic potential of natural killer (NK) cells has been of rising interest in recent years. Interactions between inhibitory killer cell immunoglobulin-like receptors (KIR) and HLA class I ligands seem to be critically involved in the immunosurveillance process. It is also well established that mismatching of HLA class I-encoded KIR ligands in the setting of hematopoietic stem cell transplantation leads to allorecognition of leukemic cells by NK cells, which is in line with the concept of missing-self recognition. Recent data now suggest that $K I R$ gene polymorphism constitutes another important parameter that needs to be taken into account for selection of suitable stem cell donors. Moreover, the role of $K I R$ gene polymorphism for predisposition to leukemia is a current matter of debate. Here, we would like to review the role of KIR function and genetic polymorphism for recognition of leukemia and discuss the impact of these findings for developing novel concepts for NK cell-based immunotherapy strategies.

Keywords: NK cells, KIR, leukemia, ALL, AML, oncology, HSCT

\section{INTRODUCTION}

Natural killer (NK) cells represent a subset of innate lymphoid cells that act as first line of defense against viral infections, early cellular transformation and tumor growth (Lanier, 2005; Spits and Di Santo, 2011). The "missing-self" concept, put forward by Kärre and colleagues in the 1980s, formed the basis for understanding NK-derived allorecognition by describing one simplistic mechanism by which NK cells target tumor cells deficient in MHC-I expression (Kärre et al., 1986; Lanier, 2005). According to this hypothesis NK cells expressing a cognate inhibitory receptor for the respective major histocompatibility complex (MHC) class I molecule can detect target cells via their reduced or "missing" expression of "self" MHC class I (Ljunggren and Karre, 1990; Algarra et al., 1997). In humans this is based on human leukocyte antigen (HLA) class I-specific receptors, which are mainly encoded by the killer cell immunoglobulin-like receptor (KIR) family and the lectin-like receptor family of NKG2 genes. Additional MHC class I receptors are encoded by the LIR gene family (Colonna et al., 1997; Cosman et al., 1997). KIRs are the genetically most polymorphic of these receptors, interacting with the equally polymorphic HLA class I system. In rodents, in the absence of KIR genes, a comparable MHC class I-specific system is in place encoded by the Ly49 family (Karlhofer et al., 1992; Raulet et al., 1997; Trowsdale et al., 2001).

Killer cell immunoglobulin-like receptors recognize specific motifs of HLA class I molecules, which are the products of highly polymorphic genes of the MHC located on chromosome 6 (Klein and Sato, 2000a,b; Vilches and Parham, 2002; Marsh et al., 2010). HLA-C plays a key role for KIR-mediated recognition of target cells and all allelic variants invariably provide ligands for inhibitory KIR. All HLA-C allotypes carry valine (V) at position 76 , while position 80 displays a dimorphism of either asparagine or lysine. HLA-C group 1 with asparagine at position 80 provides the ligand for KIR2DL2 and KIR2DL3, whereas HLA-C group 2 with lysine at position 80 provides the ligand for KIR2DL1. However, it has been shown recently that KIR2DL2 and to a lesser extend KIR2DL3 bind to certain HLA-C2 group alleles as well, while KIR2DL1 exhibits exquisite specificity for HLA-C2 only (Moesta et al., 2008). KIR3DL1 binds the HLA-B motif Bw4, which is also present on some HLA-A molecules whereas KIR3DL2 has specificity for HLA-A alleles (A3 and A11) but also for CpG oligonucleotides (Marcenaro et al., 2009). The ligand specificity of stimulatory KIR is less well described with the exception of KIR2DS1. Activating KIR2DS1 and inhibitory KIR2DL1 share ligand specificity for the HLA-C2 group, which is consistent with their highly similar extracytoplasmic domain. In case of KIR2DS4, weak but significant interactions with subsets of HLA-C alleles as well as HLA-A ${ }^{\star} 11$ could be detected (Graef et al., 2009). The ligands of KIR3DS1 have yet to be identified but recent studies have suggested that the HLA-Bw4-T80 allotype HLA-B ${ }^{\star 2} 205$ is a potential putative ligand for KIR3DS1 (Martin et al., 2002; Alter et al., 2007, 2009; Korner and Altfeld, 2012). Specificity of the stimulatory KIR KIR2DS2, KIR2DS3, and KIR2DS5 is not known and might comprise also non-HLA ligands (Kim et al., 1997; Vales-Gomez et al., 1998; Winter et al., 1998; Vilches and Parham, 2002; Carr et al., 2007; Della Chiesa et al., 2008; VandenBussche et al., 2009).

Killer cell immunoglobulin-like receptors are displayed on the surface of NK cells in diverse combinations. This clonallydistributed expression mode leads to the generation of complex NK cell repertoires, which basically comprise NK cells expressing all possible combinations of receptors (Valiante et al., 1997; Raulet et al., 2001; Yawata et al., 2006; Andersson et al., 2010; Schonberg et al., 2011a). The clonal expression mode and the cell type specificity of KIR genes are epigenetically regulated on the levels of DNA methylation and histone modifications in addition to promoter-derived transcriptional regulation (Uhrberg, 2005b). 


\section{NK CELL-MEDIATED TUMOR SURVEILLANCE}

Natural killer cell function is determined by the net effect of signaling through several receptor families including activating, inhibiting, adhesion, and cytokine receptors. In this way, NK cells have demonstrated not only the ability of killing virally infected cells, but also of exerting antitumor cytotoxicity against lymphoblastic or myeloid hematologic malignancies and solid tumors like ovarian, breast, and colon cancer (Pende et al., 2005; Re et al., 2006; Stein etal., 2006). Notably, it has been shown that cytotoxicity of NK cells in the peripheral blood of leukemia patients is significantly reduced (Costello et al., 2002; Fauriat et al., 2007). Various mechanisms and characteristics could account for this reduced cytotoxicity: (a) an increased expression of MHC class I on leukemic blasts, (b) a reduced expression of ligands of various stimulatory NK cell receptors like NKG2D, NCR, and KIR on leukemic blasts, and (c) a reduced expression of these activating receptors on NK cells of patients with leukemia (Nowbakht et al., 2005; Szczepanski et al., 2010). Most of the investigations so far concerning the role of NK cells in leukemia dealt with adult patients suffering from acute myeloid leukemia (AML; Moretta et al., 2011). Little is known regarding the role of NK cells in the emergence and prevention of acute lymphoblastic leukemia (ALL), especially in the pediatric setting. Several studies suggest a less efficient interaction between NK cells and ALL blasts compared to the interaction between NK cells and AML blasts at the time of diagnosis (Nasrallah and Miale, 1983; Ruggeri et al., 2008). In this regard, surface density of HLA class I molecules seems to be higher on ALL compared to AML blasts (Pende et al., 2005). Other mechanisms of immune escape in ALL might be the absence or down-regulation of ligands for activating NK cell receptors and the expression of ligands for inhibitory receptors. Remarkably, information on the expression of KIR on NK cells of patients suffering from acute leukemia is scarce. Thus, the influence of an emerging acute or chronic leukemia on the functional NK cell repertoire as well as the question of adaptation to self-HLA class I and the licensing status in ALL patients remain to be analyzed in detail.

In HLA class I-matched hematopoietic stem cell transplantation (HSCT), NK cells were shown to contribute to leukemia surveillance based on the specific make-up of their KIR locus (Cooley et al., 2009, 2010). Interestingly, stimulatory KIR genes are emerging as important variables in this process (Venstrom et al., 2012). Since specificity of most of the stimulatory KIR genes is not well defined, the precise mechanism of their contribution constitutes a challenging but important question.

\section{LICENSING AND ALLOREACTIVITY}

Since KIR and HLA class I genes segregate on different chromosomes, a tolerance mechanism has to be in place to prohibit development of autoreactive NK cells, e.g., NK cells with an inhibitory KIR for HLA class I ligands not present in the genome. NK cells expressing orphan inhibitory KIR are indeed present in most NK cell repertoires and pose a potential threat (Anfossi et al., 2006). However, only NK cells expressing inhibitory receptors for self-HLA class I acquire full functional competence, whereas potential autoreactive NK cells remain in a hyporesponsive state, a process referred to as education or licensing (Fernandez et al.,
2005; Kim et al., 2005, 2008; Anfossi et al., 2006; Yu et al., 2007; Yawata et al., 2008).

In clinical stem cell transplantation, licensed NK cells become potentially alloreactive when transferred in an HLA class I mismatched patient. Moreover, non-licensed NK cells might be reactivated in the cytokine-rich environment of the reconstituting hematopoietic system, providing an additional source of alloreactive NK cells (Hsu et al., 2005, 2006; Clausen et al., 2007; Miller et al., 2007). In this regard, it could be shown that NK cells can be aberrantly activated after transplantation and achieve effector function and functional competence in spite of lacking class I ligand for donor inhibitory KIR (Hsu et al., 2005, 2006; Clausen et al., 2007; Miller et al., 2007; Yu et al., 2009). Moreover, Yu et al. (2009) revealed that in HSCT settings "unlicensed" NK cells with inhibitory KIR for non-self-HLA are functional while "licensed" NK cells with inhibitory KIR for self-HLA appeared to be hyperresponsive. These findings were opposed by Bjorklund et al. (2010) who demonstrated that NK cells without self-HLA receptors remained hyporesponsive after HSCT thus remaining tolerant. In contrast, Vago et al. (2008) showed a general hyporesponsiveness of NK cells in the presence of leukemic blasts. Licensed and unlicensed NK cell subsets with alloreactive potential can be qualitatively predicted in the HSCT setting as outlined in Table 1 and the size of the alloreactive populations estimated by flow cytometry.

Another interesting facet of KIR-mediated alloreactivity is given by the recently described education of stimulatory KIR. It was shown that NK cells expressing KIR2DS1, which is an activating receptor specific for the HLA-C2 allotype are functional only when derived from HLA-C1/C2 or HLA-C1/C1 donors but hyporesponsive in donors homozygous for HLA-C2. The data imply that expression of KIR2DS1 in the presence of HLA-C2 generally renders NK cells hyporesponsive independent of inhibitory KIR or

\section{Table 1 | Pattern of NK cell licensing and alloreactivity for HLA-C-encoded KIR ligands.}

\begin{tabular}{|c|c|c|c|c|c|}
\hline \multirow{2}{*}{$\begin{array}{l}\text { Donor } \\
\text { KIR ligand }\end{array}$} & \multicolumn{2}{|c|}{ Education } & \multirow{2}{*}{$\begin{array}{l}\text { Recipient } \\
\text { KIR ligand }\end{array}$} & \multicolumn{2}{|c|}{ Alloreactive NK cells } \\
\hline & Licensed & Unlicensed & & Licensed & Unlicensed \\
\hline $\mathrm{C} 1 / \mathrm{C} 1$ & KIR2DL3 & KIR2DL1 & $\mathrm{C} 1 / \mathrm{C} 1$ & - & KIR2DL1 \\
\hline $\mathrm{C} 1 / \mathrm{C} 2$ & $\begin{array}{l}\text { KIR2DL1/ } \\
\text { KIR2DL3 }\end{array}$ & - & $\mathrm{C} 1 / \mathrm{C} 1$ & KIR2DL1 & - \\
\hline $\mathrm{C} 2 / \mathrm{C} 2$ & KIR2DL1 & KIR2DL3 & C1/C1 & KIR2DL1 & - \\
\hline $\mathrm{C} 1 / \mathrm{C} 1$ & KIR2DL3 & KIR2DL1 & $\mathrm{C} 1 / \mathrm{C} 2$ & - & - \\
\hline $\mathrm{C} 1 / \mathrm{C} 2$ & $\begin{array}{l}\text { KIR2DL1/ } \\
\text { KIR2DL3 }\end{array}$ & - & $\mathrm{C} 1 / \mathrm{C} 2$ & - & - \\
\hline $\mathrm{C} 2 / \mathrm{C} 2$ & KIR2DL1 & KIR2DL3 & $\mathrm{C} 1 / \mathrm{C} 2$ & - & - \\
\hline $\mathrm{C} 1 / \mathrm{C} 1$ & KIR2DL3 & KIR2DL1 & $\mathrm{C} 2 / \mathrm{C} 2$ & KIR2DL3 & - \\
\hline $\mathrm{C} 1 / \mathrm{C} 2$ & $\begin{array}{l}\text { KIR2DL1/ } \\
\text { KIR2DL3 }\end{array}$ & - & $\mathrm{C} 2 / \mathrm{C} 2$ & KIR2DL3 & - \\
\hline $\mathrm{C} 2 / \mathrm{C} 2$ & KIR2DL1 & KIR2DL3 & $\mathrm{C} 2 / \mathrm{C} 2$ & - & KIR2DL3 \\
\hline
\end{tabular}

Of note, to keep the scheme simple the contribution of KIR2DL2 and KIR2DS1 were not considered here. 
CD94/NKG2A expression (Fauriat et al., 2010). In line with this, in a recent evaluation of allogeneic HSCT for AML, grafts possessing KIR2DS1 on a C1/C1 background were associated with the lowest incidence of relapse (Venstrom et al., 2012). However, no significant effect of KIR2DS1 was seen in C2/C2 patients, which generally exhibited worse outcome compared to $\mathrm{C} 1 / \mathrm{C} 1$. It was thus suggested that the lack of $\mathrm{C} 2 / \mathrm{C} 2$ (or alternatively the presence of $\mathrm{C} 1 / \mathrm{C} 1)$ is another dominant genetic influence in AML patients that is independent of KIR2DS1 (Fischer et al., 2007; Fischer and Uhrberg, 2012). Remarkably, Pende et al. (2009) reported that KIR2DS1-expressing NK cell clones generated from C2/C2 recipients following haploidentical transplantation were highly cytolytic against patients' C2/C2 leukemic blasts and overriding inhibition by NKG2A or inhibitory KIR. Clearly, the clinical role of KIR2DS1 and other stimulatory KIR for NK cell alloreactivity should be clarified in further studies.

\section{DEVELOPMENT OF ALLOGENEIC NK CELL REPERTOIRES}

Natural killer cells develop from hematopoietic progenitor cells (HPC) in distinct stages, defined by a panel of surface markers (Yokoyama et al., 2004; Freud et al., 2006; Caligiuri, 2008). NK progenitor cells $\left(\mathrm{CD} 34^{\mathrm{dim}} / \mathrm{CD} 117^{-} / \mathrm{NKG} 2 \mathrm{~A}^{-}\right)$differentiate into immature $\mathrm{CD}^{2} 6^{+} \mathrm{NK}$ cells, which still lack the CD94/NKG2A heterodimer $\left(\mathrm{CD} 34^{-} / \mathrm{CD} 117^{+} / \mathrm{CD} 6^{+/-}\right)$. In a next step, these immature NK cells develop into CD56 ${ }^{\text {bright }} \mathrm{NK}$ cells, which express CD94/NKG2A (CD34-/CD117 $\left.+/-/ C D 94^{+}\right)$. Finally, mature NK cells are characterized by CD56 ${ }^{\mathrm{dim}}, \mathrm{CD} 6^{+}$and either NKG2A or KIR expression $\left(\mathrm{CD} 34^{-} / \mathrm{CD} 117^{-} / \mathrm{CD} 4^{+} / \mathrm{CD} 16^{+} / \mathrm{KIR}^{+}\right.$; Freud et al., 2006). In this context, it was already shown that CD56 bright cells found in peripheral blood and secondary lymphoid organs can be directly differentiated into mature $\mathrm{CD} 56^{\mathrm{dim}} \mathrm{CD} 16^{+} \mathrm{NK}$ cells (Ferlazzo et al., 2004; Chan et al., 2007; Romagnani et al., 2007; Huntington et al., 2009).

After HSCT, NK cells are known to be the lymphocyte subset showing the fastest reconstitution in vivo, which is a prerequisite to efficiently exert antileukemic effects early after HSCT (Pfeiffer et al., 2010). They are $\mathrm{CD}^{+} 6^{+}$and predominantly CD16 and $\mathrm{KIR}^{-}$. It could be shown that CD56 ${ }^{\mathrm{dim}} \mathrm{NK}$ cells from patients who recently underwent hematopoietic transplantation transiently overexpress NKG2A, compared with cells from healthy donors (Dulphy et al., 2008; Vago et al., 2008; Beziat et al., 2009, 2010). In many respects, the early recovering NK cells closely resemble the CD56 $6^{\text {bright }}$ subset of peripheral blood NK cells, whereas the fraction of cells corresponding to the CD56 ${ }^{\mathrm{dim}} \mathrm{CD} 16^{+}$ $\mathrm{NK}$ cell fraction increases and predominates at later times after transplantation (Shilling et al., 2003). This orderly appearance of $\mathrm{CD} 56^{\text {bright }}$ and $\mathrm{CD} 56^{\mathrm{dim}} \mathrm{CD} 16^{+}$subsets supports the model that $\mathrm{CD} 56^{\text {bright }}$ cells are the principal progenitors of mature CD56 ${ }^{\text {dim }} \mathrm{CD} 16^{+}$NK cells.

Another factor that influences the composition of allogeneic NK cell repertoires following HSCT is the sequential mode of KIR acquisition during $\mathrm{NK}$ cell differentiation. In vitro, $\mathrm{NK}$ cell differentiation from hematopoietic progenitors leads to early expression of KIR2DL2/3 whereas KIR2DL1 is only expressed at later time points (Miller and McCullar, 2001; Schonberg et al., 2011b). The model of differentiation is given in Figure 1. Similar observations were made in studies following the reconstitution of
NK cell repertoires following HSCT (Shilling et al., 2003). These patterns of expression influence the overall frequency of functionally competent NK cells including putative leukemia-reactive clones. In this context, it could be shown that the presence of HLA-C1, which is the ligand for the early-expressed KIR receptor KIR2DL3 was associated with increased survival if present in the recipient, whereas the presence of HLA-C2 ligands in the recipient constituted a risk factor (Fischer et al., 2007). These findings were in line with previous clinical observations (Giebel et al., 2003; Hsu et al., 2005). Notably, HLA-C allele matching (four-digit level) had differential effects in HLA-C1 (C1/C1) and HLA-C2 (C1/C2 and C2/C2) subgroups of patients: in HLA-C1 patients with myeloid leukemia, HLA-C-matching was associated with improved survival as described previously (Morishima et al., 2002; Flomenberg et al., 2004; Petersdorf et al., 2004; Woolfrey et al., 2011). Surprisingly, the opposite was true for HLA-C2 patients, which profited from having an HLA-C allele mismatch on the allelic level (Fischer et al., 2012), i.e., two different HLA$\mathrm{C}$-alleles that both belong to the HLA-C2 ligand group. HLA-C2 patients with these allele-mismatched, but "KIR-neutral" donors generally showed superior survival with substantial improvement in treatment related mortality and relapse incidence compared to HLA-C1 patients with HLA-C mismatches. The data suggest that HLA-C mismatching should be avoided in HLA-C1 patients as reported previously but might be favorable for HLAC2 patients. Furthermore, the study suggested a novel model in which matched HLA-C1 and mismatched HLA-C2 patients constitute a low-risk group, whereas mismatched HLA-C1 and matched HLA-C2 patients would represent a high-risk group with inferior overall survival, increased TRM and higher relapse rate [in myeloid leukemia and myelodysplasia syndrome (MDS); Fischer et al., 2012].

\section{KIR GENETICS AND ALLOREACTIVITY}

Two KIR haplotype groups, $A$ and $B$, have been identified based on differential KIR gene content (Uhrberg et al., 1997). Group $A$ and $B$ haplotypes have four framework genes in common: the KIR gene cluster is flanked by the non-expressed KIR3DL3 at the centromeric end, KIR3DL2 at the telomeric end, with KIR3DP1 and KIR2DL4 in the middle. Deletion and duplication of genes have led to many different haplotypes (Vierra-Green et al., 2012). Group A haplotypes are present in all populations and consist of five productive inhibitory KIR (KIR2DL3, KIR2DL1, KIR2DL4, KIR3DL1, $K I R 3 D L 2)$, and the stimulatory KIR2DS4, which is frequently present in an allelic variant that is not expressed on the cell surface (Maxwell et al., 2002). Group B comprises KIR haplotypes with diverse gene content including several genes (KIR2DL2, KIR2DL5, KIR2DS1, KIR2DS2, KIR2DS3, KIR2DS5, and KIR3DS1) that are not part of group $A$ haplotypes. As a consequence, most group $B$ haplotypes encode more activating KIRs compared to group $A$ haplotypes. All individuals can be categorized as having one of two KIR genotypes: $A / A$, which is homozygous for group $A$ KIR haplotypes, or $B / x$, which contains either one ( $A / B$ heterozygotes) or two ( $B / B$ homozygotes) group $B$ haplotypes.

There have only been a few studies regarding the impact of genetic polymorphisms of activating and inhibitory KIR in humans on the susceptibility and resistance to leukemia. 


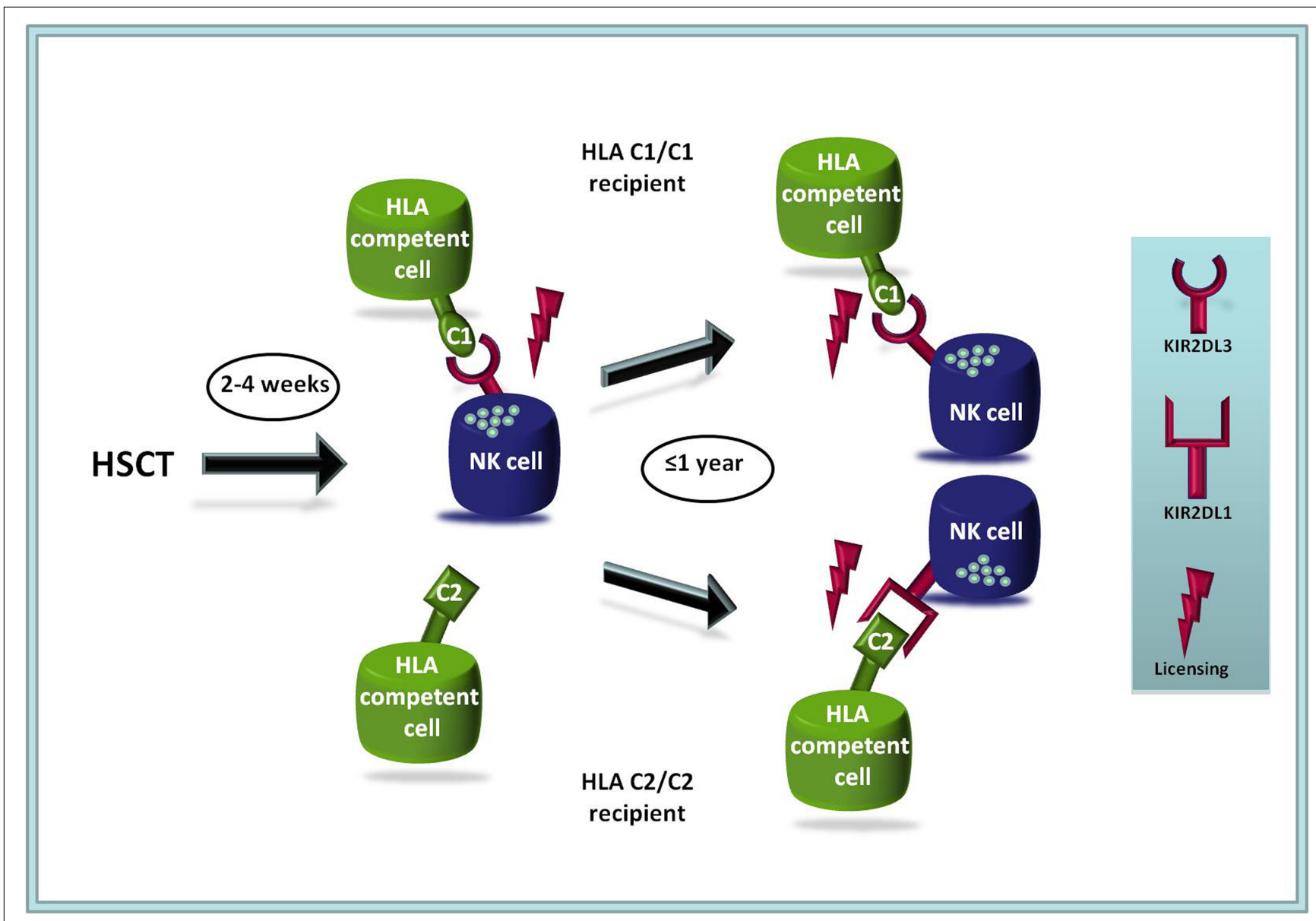

FIGURE 1 | Model of NK cell reconstitution and NK cell receptor expression following allogeneic HSCT. The HLA-C1-specific

$\mathrm{KIR} 2 \mathrm{DL} 2 / 3$ receptor is expressed at earlier time points on reconstituting NK cells than the HLA-C2-specific KIR2DL1 (Shilling et al., 2003; Nguyen et al., 2005; Fischer et al., 2007). Thus, in the clinical setting C2/C2 recipients possess a lower frequency of functionally competent NK cells (expressing KIR2DL1) than C1/C1 patients (expressing KIR2DL2/3), which may lead to a disadvantage in the early phase following HSCT. The model is compatible with decreased overall survival rates and increased relapse rates in $\mathrm{C} 2 / \mathrm{C} 2$ individuals that were found in several different studies (Fischer etal., 2007, 2012; Venstrom et al., 2012).
Verheyden et al. (2004) revealed an association of the inhibitory KIR2DL2 gene with leukemia. In a polymorphic cohort of AML, ALL, CML (chronic myeloid leukemia), and CLL (chronic lymphoblastic leukemia) patients they found a significantly increased frequency of the KIR haplotype combination $A / B$ in leukemic patients compared to controls. This finding was related to the high prevalence of the inhibitory KIR2DL2 gene. Another significant association with leukemia was found for two distinct KIR genotypes, which included all inhibitory KIRs (Uhrberg et al., 2002; Verheyden and Demanet, 2008). In a more recent study of pediatric ALL patients, Almalte et al. (2011) reported a highly significant association between the presence of stimulatory KIR genes and decreased risk for ALL. The risk for ALL progressively decreased with the cumulative number of stimulatory KIR. In a subsequent study, no significant association was found between childhood ALL and stimulatory KIR genes (Babor et al., 2012). In the latter study neither stimulatory nor inhibitory genes exhibited a significant deviation in frequency from an ethnically matched control group. Analyses of the cumulative number of stimulatory and inhibitory KIR genes as well as further analysis of telomeric and centromeric KIR haplotypes did not reveal any significant difference to the control cohort. Similarly, in a recent study analyzing a large cohort of AML patients, frequencies of stimulatory KIR genes were again not different to published healthy donor cohorts (Venstrom et al., 2012). More thorough analysis of KIR genes on the allelic level will be necessary to settle the question if KIR genes constitute a major disease susceptibility locus for acute leukemia in children and adults. Notably, the identification of single KIR genes as disease markers is generally complicated by the fact that groups of KIR genes are tightly linked in a small number of common centromeric and telomeric haplotypes (Uhrberg, 2005a). Moreover, centromeric KIR genes could be linked to the neighboring LIR gene family including inhibitory and stimulatory LIR genes that are known to be expressed on NK cells as well (Cosman et al., 1997; Young et al., 2001).

In the clinical transplant setting, Stringaris et al. (2010) revealed that three donor $B$ haplotype KIR genes, KIR2DL5A, KIR2DS1, and KIR3DS1, were associated with significantly less relapse in 
patients with AML undergoing HLA-identical sibling HSCT. The authors could not confirm these findings in patients with other myeloid or lymphoid malignancies. Recent data suggest evidence of beneficial effects of KIR $B$ genotype donors in AML patients in an unrelated HLA-matched HSCT setting (Cooley et al., 2009, 2010). Cooley et al. (2009) analyzed the effect of KIR genotypes on outcome in a comparatively homogeneous study cohort of 448 AML patients who received T cell replete transplants from unrelated donors. They could show that the use of donors with KIR group $B$ haplotypes was associated with significant improvement in relapse-free and overall survival, with $30 \%$ better relative risk in both endpoints. The same group subsequently performed analyses regarding gene content motifs, which further revealed that compared with group $A$ haplotype motifs, centromeric and telomeric group $B$ motifs both contributed to relapse protection and improved survival. Centromeric B homozygosity $(C e n-B / B)$ had the strongest independent effect. Overall, significantly reduced relapse was achieved with donors having two or more $B$ genecontent motifs in both HLA-matched and mismatched transplants (Cooley et al., 2010). In contrast, Venstrom et al. (2012) revealed in their study of AML transplant patients a beneficial effect of telomeric but not centromeric genes, namely KIR2DS1 and KIR3DS1. Together, these findings highlight the need for further studies of KIR polymorphism in HSCT, possibly on the allelic level, to enable incorporation of KIR gene content status along with HLA-matching in future algorithms for donor selection in allogeneic/haploidentical HSCT settings.

\section{EXPLOITING KIR AND KIR LIGAND MISMATCHING IN HSCT}

In HSCT settings, donor-derived $\mathrm{T}$ cells are essential not only for early cellular engraftment following HSCT but also for eradication of remaining leukemic blasts. On the other hand, $\mathrm{T}$ cells are major effectors of rejection or acute or chronic graft versus host disease (GvHD). T cell-mediated alloreactivity is directed against histocompatibility antigens not only displayed on the stem cell recipient's leukemic cells but also on other tissues. Especially cytotoxic $\mathrm{CD}{ }^{+}$effector $\mathrm{T}$ cells may then attack tissues such as liver, intestines, and skin, which results in acute or chronic GvHD. Currently, in order to avoid GvHD various manipulations of HSCT grafts such as CD6 ${ }^{+}$T cell depletion (Soiffer et al., 2001), $\mathrm{CD}^{+} / \mathrm{CD} 19^{+} \mathrm{T}$ and $\mathrm{B}$ cell depletion (Federmann et al., 2012) or $\alpha / \beta \mathrm{T}$ cell (Handgretinger, 2012) depletion are implemented in different transplant centers. With this approach, the numbers of potentially graft rejecting or GvHD causing T cells can be reduced considerably while HPC and NK cells remain in the graft and can be transferred into the patient. Such grafts, mainly consisting of mature NK cells, CD34 ${ }^{+}$stem cells and only a few remaining $\mathrm{T}$ cells (max. $5 \times 10^{4} / \mathrm{kg} \mathrm{BW}$ ) of donor origin repopulate the recipient's hematopoietic system and rebuild the recipient's new immune system that quickly reconstitutes immunity to viral and bacterial infections and eliminates leukemic blasts that survived chemotherapy (graft versus leukemia effect - GvL). Especially in $\mathrm{CD}^{+} / \mathrm{CD} 9^{+}$depleted grafts large numbers of mature donor NK cells are co-transfused.

Previous in vitro studies already demonstrated the alloreactive potential of NK cells (Ciccone et al., 1992; Colonna et al., 1992) and showed that the kind and frequency of alloreactive NK cells can be predicted if KIR expression in the donor and presence of KIR ligands in the recipient are known (Valiante et al., 1997). The clinical contribution of NK cells to alloreactivity was impressively shown by Ruggeri et al. (2002) who demonstrated a strong GvL effect for AML patients receiving a haploidentical allogeneic transplant mismatched for HLA-C KIR ligands. In this setting alloreactive donor-derived NK cells are thought to promote engraftment, reduce GVHD, and decrease leukemic relapse. Whereas some subsequent studies did confirm the KIR ligand mismatch model (Giebel et al., 2003) others could not find a beneficial effect of KIR ligand mismatching (Davies et al., 2002; Hsu et al., 2006; Miller et al., 2007), which might be explained by specific differences in HSCT protocols performed in the different transplant centers. Subsequently, several modified donor selection models were suggested based on the consideration that donor NK cells expressing a certain inhibitory KIR would be alloreactive if the respective ligands (C1, C2, or Bw4) in the patient are missing. This model was originally proposed by Leung et al. (2004) and demonstrated better clinical outcome in haploidentical HSCT for pediatric lymphoid leukemia thereby proofing that NK cell-mediated relapse control is not restricted to myeloid leukemia. Hsu et al. (2005) applied the same model to HLA-identical HSCT showing that patients with missing KIR ligands for which the donor possessed a specific KIR exhibited increased survival through decreased relapse incidence in AML and MDS patients. An overview of studies investigating the role of KIR genes in clinical stem cell transplantation is given in Table 2.

\section{NK CELL IMMUNOTHERAPY: ONLY AT THE BEGINNING OF GREAT POSSIBILITIES?}

Cytokines such as IL-2, IL-15, and IL-21, as well as the combination of IL-12 and IL-18 are known to activate NK cells (Carson et al., 1995; Singh et al., 2000; Trinchieri, 2003; Young and Ortaldo, 2006). Coadministration of such NK cell-activating cytokines have the potential to increase survival of adoptively transferred NK cells, enhance proliferation, up-regulation of cytotoxic and adhesion molecules, augment cytokine production and increase GvL effects (Becknell and Caligiuri, 2005). IL-2 activated NK cells kill tumor cells in vitro and in vivo by localizing to the tumor sites to elicit their cytotoxic action and they prolong the survival of tumor bearing mice. This was seen in mice with multiple myeloma (Alici et al., 2007) and in NOD/SCID mice with metastatic neuroblastoma (Castriconi et al., 2004). Unfortunately, administered cytokines such as IL-2, IL-15, or IL-18 are rapidly cleared, thus requiring repeated injections (subcutaneous) of large amounts. This in turn increases the potential for toxicity considerably and furthermore might elicit activation of unwanted cell populations or even cause activation-induced cell death of NK cells. IL-2 but not IL-15 is known to be involved in the maintenance of T regulatory cells (Treg), which could impair antitumor immune response (Waldmann, 2006). Thus, IL-15 administration holds promise to specifically boost NK cell alloreactivity without undesired stimulation of Tregs. Importantly, the use of IL-15 as GMP product has recently been approved by the U.S. Food and Drug Administration (FDA). However, since full biological activity of IL-15 is dependent on its trans-presentation on the cell surface, suitable application strategies have to be developed to increase biological stability and 
Table 2 | An overview of studies analyzing the role of KIR for susceptibility and clinical HSCT for leukemia.

\begin{tabular}{|c|c|c|c|c|c|}
\hline \multirow[t]{2}{*}{ Genetic associations } & KIR2DL2 & Increased frequency & AML/ALL & - & Nerheyden et al., 2004) \\
\hline & KIR-L / KIR-S & No association & ped ALL & - & (Babor et al., 2012) \\
\hline \multirow[t]{3}{*}{ Inhibitory KIR } & Missing KIR ligand & Relapse $\downarrow$ & ped. AML/ALL & Haploidentical & (Leung et al., 2004) \\
\hline & KIR ligand mismatch & Relapse $\downarrow$, Survival $\uparrow$ & AML & Haploidentical & (Ruggeri etal., 2007) \\
\hline & KIR3DL1 & Survival $\downarrow$ & Acute leukemia & Unrelated HSCT & (Gagne et al., 2009) \\
\hline \multirow[t]{3}{*}{ Stimulatory KIR } & KIR2DS2 & Survival $\downarrow$ & AML (ALL) & MSD HSCT & (Cook etal., 2004) \\
\hline & KIR3DS1 & Survival $\downarrow$ & Acute leukemia & Unrelated HSCT & (Gagne etal., 2009) \\
\hline & KIR2DS1 & Relapse $\downarrow$ & AML & Unrelated HSCT & Nenstrom et al., 2012) \\
\hline
\end{tabular}

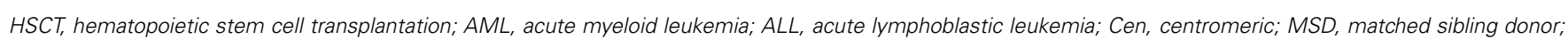
ped, pediatric; indiv, individuals.

activity. These include administration of pre-associated complexes of IL-15 with soluble IL-15R $\alpha$-IgG1-Fc or stimulation of native IL-15R $\alpha$ expression with, e.g., anti-CD40 (Zhang et al., 2009; Steel et al., 2012).

Advanced cell therapy trials with donor NK cells posthaploidentical stem cell transplantation provide a promising treatment option for patients with high risk leukemia and tumors (Leung et al., 2004, 2005). While the established adoptive T cell therapies are associated with the risk of GvHD, NK cells mediate GvL effects without substantial induction of acute GvHD. These findings encouraged scientists and clinicians to conduct clinical trials utilizing adoptive transfer of cytokine-activated NK cells, which could serve as an attractive cell therapy option not only in recipients of haploidentical stem cell transplantation but in other oncologic diseases as well (Miller et al., 2005; Passweg et al., 2006; Rubnitz et al., 2010). In 2005, Miller and colleagues were the first to infuse haploidentical NK cells into AML recipients in a non-transplant setting (Miller et al., 2005). Before NK cell infusion patients received an intensive immunosuppressive regimen of low-dose cyclophosphamide and methylprednisolone or fludarabine. Successful transfer of haploidentical KIR ligand-mismatched NK cells was followed by a subcutaneous administration of IL-2 for 2 weeks. NK cells expanded in vivo and were functional at day 14 following infusion (Miller et al., 2005). But still, the intensive conditioning regimen and high doses of IL-2 resulted in significant hematologic and non-hematologic toxicities as well as prolonged hospitalization. In order to further optimize this strategy of donor-derived NK cell transfer, Rubnitz etal. (2010) extended investigations concerning the safety and feasibility of low-dose immunosuppression followed by NK cell infusion. This study on transfer of alloreactive haploidentical KIR ligand-mismatched NK cells has been performed in children with AML after achievement of complete remission. In order to minimize toxicity while still allowing engraftment of haploidentical NK cells a low-intensity regimen was administered to patients followed by NK cell infusion and multiple doses of IL-2. The study gave encouraging results, and has allowed commencement of a phase II trial as consolidation therapy in children with AML. In multiple myeloma, infusion of haploidentical KIR ligand-mismatched NK cells after conditioning therapy with melphalan and fludarabine has been proposed in relapsed patients (Shi et al., 2008). Curti et al. (2011) demonstrated that infusion of purified NK cells is feasible and safe in elderly patients with high-risk AML and these donor alloreactive NK cells were shown to kill recipient leukemia cells. Again, no NK cellrelated toxicity, including GVHD, was observed. Donor-versusrecipient alloreactive NK cells were shown in vivo by the detection of donor-derived NK clones that killed recipient's targets.

Together, these trials show that adoptive immunotherapy with haploidentical NK cells obtained from KIR ligand-mismatched donors is feasible and safe in adults as well as in children. Nevertheless, further studies are highly warranted to specifically assess the role of NK cell therapy to elucidate which patient collective (AML/ALL/adults/children) is best suited at which stage of disease (remission/relapse) and at which stage of therapy (after/prior to/without HSCT). Furthermore, these studies should address the question, which NK cell subset (single $\mathrm{KIR}^{+} \mathrm{NK}$ cells, licensed or unlicensed) mediates strongest reactivity against leukemia.

\section{CONCLUSION}

KIR genes have two unusual features that could be harnessed for improving current HSCT strategies: firstly, KIR genes are highly polymorphic leading to novel opportunities beyond classical HLA matching strategies for selection of optimal stem cell donors based on KIR genetic diversity. Secondly, KIR are expressed in a clonally distributed manner, which leads to the formation of NK cell repertoires encompassing tolerant as well as potentially alloreactive NK cell clones. Both features have a great potential to be exploited in the setting of clinical stem cell transplantation. 
While recent studies could not detect a predisposition for leukemia based on presence or absence of particular inhibitory and stimulatory KIR genes or KIR haplotype classification, there is growing evidence for beneficial effects of KIR B genotype donors in HSCT for AML. In general, NK cells and their variable capability of killing residual leukemic blasts become a criterion of growing importance as clinicians are offered another important factor concerning donor selection in unrelated, sibling, and haploidentical transplant settings along with HLA matching, CMV status, blood group, age, and gender. Furthermore, recent investigations suggest that homozygous HLA-C2 stem cell transplant recipients constitute a high-risk group that needs special attention. In this regard, recent data suggest that survival of $\mathrm{C} 2 / \mathrm{C} 2$ patients might be improved by allele mismatching of donor/recipient pairs for HLA-C2, a novel concept that has to be confirmed in retrospective studies of larger cohorts. On the basis of optimally defined matching/mismatching strategies an important next step for successful NK cell-based intervention in HSCT will be to qualitatively and quantitatively define patient-specific alloreactive subsets among donor NK cell repertoires opening the possibility

\section{REFERENCES}

Algarra, I., Collado, A., and Garrido, F. (1997). Altered MHC class I antigens in tumors. Int. J. Clin. Lab. Res. 27, 95-102.

Alici, E., Konstantinidis, K. V., Sutlu, T., Aints, A., Gahrton, G., Ljunggren, H. G., et al. (2007). Anti-myeloma activity of endogenous and adoptively transferred activated natural killer cells in experimental multiple myeloma model. Exp. Hematol. 35, 1839-1846.

Almalte, Z., Samarani, S., Iannello, A., Debbeche, O., Duval, M., InfanteRivard, C., et al. (2011). Novel associations between activating killer-cell immunoglobulin-like receptor genes and childhood leukemia. Blood 118 , 1323-1328.

Alter, G., Martin, M. P., Teigen, N., Carr, W. H., Suscovich, T. J., Schneidewind, A., et al. (2007). Differential natural killer cell-mediated inhibition of HIV-1 replication based on distinct KIR/HLA subtypes. J. Exp. Med. 204, 3027-3036.

Alter, G., Rihn, S., Walter, K., Nolting, A., Martin, M., Rosenberg, E. S., et al. (2009). HLA class I subtypedependent expansion of KIR3DS1+ and KIR3DL1 + NK cells during acute human immunodeficiency virus type 1 infection. J. Virol. 83, 6798-6805.

Andersson, H. M., Arantes, M. J., Crawley, J. T., Luken, B. M., Tran, S., Dahlback, B., et al. (2010). Activated protein $\mathrm{C}$ cofactor function of protein S: a critical role for Asp95 in the EGF1-like domain. Blood 115, 4878-4885.

Anfossi, N., Andre, P., Guia, S., Falk, C. S., Roetynck, S., Stewart, C. A., et al.
(2006). Human NK cell education by inhibitory receptors for MHC class I. Immunity 25, 331-342.

Babor, F., Manser, A., Schonberg, K. Enczmann, J., Borkhardt, A., Meisel, R., et al. (2012). Lack of association between KIR genes and acute lymphoblastic leukemia in children. Blood 120, 2770-2772.

Becknell, B., and Caligiuri, M. A. (2005). Interleukin-2, interleukin-15, and their roles in human natural killer cells. Adv. Immunol. 86, 209-239.

Beziat, V., Descours, B., Parizot, C., Debre, P., and Vieillard, V. (2010). NK cell terminal differentiation: correlated stepwise decrease of NKG2A and acquisition of KIRs. PLoS ONE 5:e11966. doi: 10.1371/journal.pone.0011966

Beziat, V., Nguyen, S., Lapusan, S. Hervier, B., Dhedin, N., Bories, D. et al. (2009). Fully functional NK cells after unrelated cord blood transplantation. Leukemia 23, 721-728.

Bjorklund, A. T., Schaffer, M., Fauriat, C., Ringden, O., Remberger, M., Hammarstedt, C., et al. (2010). NK cells expressing inhibitory KIR for non-self-ligands remain tolerant in HLA-matched sibling stem cell transplantation. Blood 115, 2686-2694.

Caligiuri, M. A. (2008). Human natural killer cells. Blood 112, 461-469.

Carr, W. H., Rosen, D. B., Arase, H., Nixon, D. F., Michaelsson, J., and Lanier, L. L. (2007). Cutting Edge: KIR3DS1, a gene implicated in resistance to progression to AIDS, encodes a DAP12-associated receptor expressed on NK cells that triggers NK cell activation. J. Immunol. 178, 647-651.

to stimulate, enrich, and expand those subsets in vitro or in vivo for immunotherapy.

Antileukemic NK cells, either allogeneic or unlicensed autologous NK cells, emerge as a feasible therapy option and might improve clinical outcome in myloid leukemia. Further integration into established HSCT protocols may indeed improve survival rates in adults and children. It will be an important task to define, which patients are most suitable for NK cell-mediated antileukemic therapy based on incorporation of multiple factors like genetic predisposition, HLA, KIR and the nature of leukemic disease. It would be desirable to expand the possible range of applications to ALL and lymphoma as well as toward NK cellbased therapy of solid tumors. Toward this goal, our biological understanding of NK cell function and interaction with leukemic target cells has to be further improved.

\section{ACKNOWLEDGMENTS}

This work was supported by grants to MU from the José Carreras Leukämie-Stiftung, the Deutsche Krebshilfe e.V, and the Deutsche Forschungsgemeinschaft (UH91/5-1 and UH91/7-1).

Carson, W. E., Lindemann, M. J., Baiocchi, R., Linett, M., Tan, J. C., Chou, C. C., et al. (1995). The functional characterization of interleukin-10 receptor expression on human natural killer cells. Blood 85, 3577-3585.

Castriconi, R., Dondero, A., Corrias, M. V., Lanino, E., Pende, D. Moretta, L., et al. (2004). Natural killer cell-mediated killing of freshly isolated neuroblastoma cells: critical role of DNAX accessory molecule-1poliovirus receptor interaction. Cancer Res. 64, 9180-9184.

Chan, A., Hong, D. L., Atzberger, A., Kollnberger, S., Filer, A. D., Buckley, C. D., et al. (2007). CD56bright human NK cells differentiate into CD56dim cells: role of contact with peripheral fibroblasts. J. Immunol. 179, 89-94.

Ciccone, E., Pende, D., Viale, O., Di Donato, C., Tripodi, G., Orengo, A. M., et al. (1992). Evidence of a natural killer (NK) cell repertoire for (allo) antigen recognition: definition of five distinct NK-determined allospecificities in humans. J. Exp. Med. 175 , 709-718.

Clausen, J., Wolf, D., Petzer, A. L., Gunsilius, E., Schumacher, P., Kircher, B., etal. (2007). Impact of natural killer cell dose and donor killercell immunoglobulin-like receptor (KIR) genotype on outcome following human leucocyte antigenidentical haematopoietic stem cell transplantation. Clin. Exp. Immunol. 148, 520-528.

Colonna, M., Navarro, F., Bellon, T., Llano, M., Garcia, P., Samaridis, J., et al. (1997). A common inhibitory receptor for major histocompatibility complex class I molecules on human lymphoid and myelomonocytic cells. J. Exp. Med. 186, 1809-1818.

Colonna, M., Spies, T., Strominger, J. L., Ciccone, E., Moretta, A., Moretta, L., et al. (1992). Alloantigen recognition by two human natural killer cell clones is associated with HLA-C or a closely linked gene. Proc. Natl. Acad. Sci. U.S.A. 89, 7983-7985.

Cook, M. A., Milligan, D. W., Fegan, C. D., Darbyshire, P. J., Mahendra, P., Craddock, C. F., et al. (2004). The impact of donor KIR and patient HLA-C genotypes on outcome following HLA-identical sibling hematopoietic stem cell transplantation for myeloid leukemia. Blood 103, 1521-1526.

Cooley, S., Trachtenberg, E., Bergemann, T. L., Saeteurn, K., Klein, J., Le, C. T., et al. (2009). Donors with group B KIR haplotypes improve relapse-free survival after unrelated hematopoietic cell transplantation for acute myelogenous leukemia. Blood 113, 726-732.

Cooley, S., Weisdorf, D. J., Guethlein, L. A., Klein, J. P., Wang, T., Le, C. T., et al. (2010). Donor selection for natural killer cell receptor genes leads to superior survival after unrelated transplantation for acute myelogenous leukemia. Blood 116, 2411-2419.

Cosman, D., Fanger, N., Borges, L., Kubin, M., Chin, W., Peterson, L., et al. (1997). A novel immunoglobulin superfamily receptor for cellular and viral MHC class I molecules. Immunity 7, 273-282.

Costello, R. T., Sivori, S., Marcenaro, E., Lafage-Pochitaloff, M., 
Mozziconacci, M. J., Reviron, D., et al. (2002). Defective expression and function of natural killer celltriggering receptors in patients with acute myeloid leukemia. Blood 99, 3661-3667.

Curti, A., Ruggeri, L., D’Addio, A., Bontadini, A., Dan, E., Motta, M. R., et al. (2011). Successful transfer of alloreactive haploidentical KIR ligand-mismatched natural killer cells after infusion in elderly high risk acute myeloid leukemia patients. Blood 118, 3273-3279.

Davies, S. M., Ruggieri, L., Defor, T., Wagner, J. E., Weisdorf, D. J., Miller, J. S., etal. (2002). Evaluation of KIR ligand incompatibility in mismatched unrelated donor hematopoietic transplants. Killer immunoglobulin-like receptor. Blood 100, 3825-3827.

Della Chiesa, M., Romeo, E., Falco, M., Balsamo, M., Augugliaro, R., Moretta, L., et al. (2008). Evidence that the KIR2DS5 gene codes for a surface receptor triggering natural killer cell function. Eur. J. Immunol. 38, 2284-2289.

Dulphy, N., Haas, P., Busson, M., Belhadj, S., Peffault De Latour, R., Robin, M., et al. (2008). An unusual CD56(bright) CD16(low) NK cell subset dominates the early posttransplant period following HLA-matched hematopoietic stem cell transplantation. J. Immunol. 181, 2227-2237.

Fauriat, C., Ivarsson, M. A., Ljunggren, H. G., Malmberg, K. J., and Michaelsson, J. (2010). Education of human natural killer cells by activating killer cell immunoglobulin-like receptors. Blood 115, 1166-1174.

Fauriat, C., Just-Landi, S., Mallet, F., Arnoulet, C., Sainty, D., Olive, D., et al. (2007). Deficient expression of NCR in NK cells from acute myeloid leukemia: evolution during leukemia treatment and impact of leukemia cells in NCRdull phenotype induction. Blood 109, 323-330.

Federmann, B., Bornhauser, M., Meisner, C., Kordelas, L., Beelen, D. W., Stuhler, G., et al. (2012). Haploidentical allogeneic hematopoietic cell transplantation in adults using CD3/CD19 depletion and reduced intensity conditioning: a phase II study. Haematologica 97, 15231531.

Ferlazzo, G., Thomas, D., Lin, S. L., Goodman, K., Morandi, B., Muller, W. A., et al. (2004). The abundant NK cells in human secondary lymphoid tissues require activation to express killer cell Ig-like receptors and become cytolytic. J. Immunol. 172, 1455-1462.
Fernandez, N. C., Treiner, E., Vance, R. E., Jamieson, A. M., Lemieux, S., and Raulet, D. H. (2005). A subset of natural killer cells achieves self-tolerance without expressing inhibitory receptors specific for self-MHC molecules. Blood 105, 4416-4423.

Fischer, J. C., Kobbe, G., Enczmann, J., Haas, R., and Uhrberg, M. (2012). The impact of HLA-C matching depends on the $\mathrm{C} 1 / \mathrm{C} 2 \mathrm{KIR}$ ligand status in unrelated hematopoietic stem cell transplantation. Immunogenetics 64, 879-885.

Fischer, J. C., Ottinger, H., Ferencik, S., Sribar, M., Punzel, M., Beelen, D. W., etal. (2007). Relevance of $\mathrm{C} 1$ and $\mathrm{C} 2$ epitopes for hemopoietic stem cell transplantation: role for sequential acquisition of HLA-Cspecific inhibitory killer Ig-like receptor. J. Immunol. 178, 3918-3923.

Fischer, J. C., and Uhrberg, M. (2012). Prevention of leukemia relapse by donor activating KIR2DS1. N. Engl. J. Med. 367, 2054-2055; author reply 2055.

Flomenberg, N., Baxter-Lowe, L. A., Confer, D., Fernandez-Vina, M. Filipovich, A., Horowitz, M., et al. (2004). Impact of HLA class I and class II high-resolution matching on outcomes of unrelated donor bone marrow transplantation: HLA$\mathrm{C}$ mismatching is associated with a strong adverse effect on transplantation outcome. Blood 104, 19231930.

Freud, A. G., Yokohama, A., Becknell, B., Lee, M. T., Mao, H. C., Ferketich, A. K., et al. (2006). Evidence for discrete stages of human natural killer cell differentiation in vivo. J. Exp. Med. 203 1033-1043.

Gagne, K., Busson, M., Bignon, J. D., Balere-Appert, M. L., Loiseau, P., Dormoy, A., etal. (2009). Donor KIR3DL1/3DS1 gene and recipient Bw4 KIR ligand as prognostic markers for outcome in unrelated hematopoietic stem cell transplantation. Biol. Blood Marrow Transplant. $15,1366-1375$

Giebel, S., Locatelli, F., Lamparelli, T., Velardi, A., Davies, S., Frumento G., et al. (2003). Survival advantage with KIR ligand incompatibility in hematopoietic stem cell transplantation from unrelated donors. Blood $102,814-819$.

Graef, T., Moesta, A. K., Norman, P. J., Abi-Rached, L., Vago, L., Older Aguilar, A. M., et al. (2009). KIR2DS4 is a product of gene conversion with KIR3DL2 that introduced specificity for HLA-A ${ }^{\star} 11$ while diminishing avidity for HLA-C. J. Exp. Med. 206, 2557-2572.
Handgretinger, R. (2012). Negative depletion of $\mathrm{CD} 3(+)$ and $\mathrm{TcR} \alpha \beta(+)$ $\mathrm{T}$ cells. Curr. Opin. Hematol. 19, 434-439.

Hsu, K. C., Gooley, T., Malkki, M., Pinto-Agnello, C., Dupont, B., Bignon, J. D., et al. (2006). KIR ligands and prediction of relapse after unrelated donor hematopoietic cell transplantation for hematologic malignancy. Biol. Blood Marrow Transplant. 12, 828-836.

Hsu, K. C., Keever-Taylor, C. A., Wilton, A., Pinto, C., Heller, G., Arkun, K. et al. (2005). Improved outcome in HLA-identical sibling hematopoietic stem-cell transplantation for acute myelogenous leukemia predicted by KIR and HLA genotypes. Blood 105, 4878-4884.

Huntington, N. D., Legrand, N., Alves, N. L., Jaron, B., Weijer, K., Plet, A., et al. (2009). IL-15 transpresentation promotes human NK cell development and differentiation in vivo. J. Exp. Med. 206, 25-34.

Karlhofer, F. M., Ribaudo, R. K., and Yokoyama, W. M. (1992). MHC class I alloantigen specificity of Ly-49+ IL2 -activated natural killer cells. Nature 358, 66-70.

Kärre, K., Ljunggren, H. G., Piontek, G., and Kiessling, R. (1986). Selective rejection of $\mathrm{H}$-2-deficient lymphoma variants suggests alternative immune defence strategy. Nature 319, 675-678.

Kim, J., Chwae, Y. J., Kim, M. Y., Choi, I. H., Park, J. H., and Kim, S. J. (1997). Molecular basis of HLA-C recognition by p58 natural killer cell inhibitory receptors. J. Immunol. 159, 3875-3882.

Kim, S., Poursine-Laurent, J., Truscott, S. M., Lybarger, L., Song, Y. J., Yang, L., et al. (2005). Licensing of natural killer cells by host major histocompatibility complex class I molecules. Nature 436, 709-713.

Kim, S., Sunwoo, J. B., Yang, L., Choi, T., Song, Y. J., French, A. R., et al. (2008). HLA alleles determine differences in human natural killer cell responsiveness and potency. Proc. Natl. Acad. Sci. U.S.A. 105, 3053-3058.

Klein, J., and Sato, A. (2000a). The HLA system. First of two parts. N. Engl. J. Med. 343, 702-709.

Klein, J., and Sato, A. (2000b). The HLA system. Second of two parts. N. Engl. J. Med. 343, 782-786.

Korner, C., and Altfeld, M. (2012). Role of KIR3DS1 in human diseases. Front. Immunol. 3:326. doi: 10.3389/fimmu.2012.00326

Lanier, L. L. (2005). NK cell recognition. Annu. Rev. Immunol. 23, 225-274.
Leung, W., Iyengar, R., Triplett, B., Turner, V., Behm, F. G., Holladay, M. S., et al. (2005). Comparison of killer Ig-like receptor genotyping and phenotyping for selection of allogeneic blood stem cell donors. J. Immunol. 174, 6540-6545.

Leung, W., Iyengar, R., Turner, V., Lang, P., Bader, P., Conn, P., et al. (2004). Determinants of antileukemia effects of allogeneic NK cells. J. Immunol. 172, 644-650.

Ljunggren, H. G., and Karre, K. (1990). In search of the "missing self": MHC molecules and NK cell recognition. Immunol. Today 11, 237-244.

Marcenaro, E., Cantoni, C., Pesce, S., Prato, C., Pende, D., Agaugue, S., etal. (2009). Uptake of CCR7 and acquisition of migratory properties by human KIR+ NK cells interacting with monocyte-derived DC or EBV cell lines: regulation by KIR/HLAclass I interaction. Blood 114, 41084116.

Marsh, S. G., Albert, E. D., Bodmer, W. F., Bontrop, R. E., Dupont, B., Erlich, H. A., et al. (2010). Nomenclature for factors of the HLA system, 2010. Tissue Antigens 75, 291-455.

Martin, M. P., Gao, X., Lee, J. H., Nelson, G. W., Detels, R., Goedert, J. J., et al. (2002). Epistatic interaction between KIR3DS1 and HLA-B delays the progression to AIDS. Nat. Genet. 31, 429-434.

Maxwell, L. D., Wallace, A., Middleton, D., and Curran, M. D. (2002). A common KIR2DS4 deletion variant in the human that predicts a soluble KIR molecule analogous to the KIR1D molecule observed in the rhesus monkey. Tissue Antigens 60, 254-258.

Miller, J. S., Cooley, S., Parham, P., Farag, S. S., Verneris, M. R., Mcqueen, K. L., et al. (2007). Missing KIR ligands are associated with less relapse and increased graft-versus-host disease (GVHD) following unrelated donor allogeneic HCT. Blood 109, 5058-5061.

Miller, J. S., and McCullar, V. (2001). Human natural killer cells with polyclonal lectin and immunoglobulinlike receptors develop from single hematopoietic stem cells with preferential expression of NKG2A and KIR2DL2/L3/S2. Blood 98, 705-713.

Miller, J. S., Soignier, Y., PanoskaltsisMortari, A., Mcnearney, S. A., Yun, G. H., Fautsch, S. K., et al. (2005). Successful adoptive transfer and in vivo expansion of human haploidentical NK cells in patients with cancer. Blood 105, 3051-3057. 
Moesta, A. K., Norman, P. J., Yawata, M., Yawata, N., Gleimer, M., and Parham, P. (2008). Synergistic polymorphism at two positions distal to the ligand-binding site makes KIR2DL2 a stronger receptor for HLA-C than KIR2DL3. J. Immunol. 180, 3969-3979.

Moretta, L., Locatelli, F., Pende, D., Marcenaro, E., Mingari, M. C., and Moretta, A. (2011). Killer Ig-like receptor-mediated control of natural killer cell alloreactivity in haploidentical hematopoietic stem cell transplantation. Blood 117, 764-771.

Morishima, Y., Sasazuki, T., Inoko, H., Juji, T., Akaza, T., Yamamoto, K., et al. (2002). The clinical significance of human leukocyte antigen (HLA) allele compatibility in patients receiving a marrow transplant from serologically HLA-A, HLA-B, and HLA-DR matched unrelated donors. Blood 99, 4200-4206.

Nasrallah, A. G., and Miale, T. D. (1983). Decreased natural killer cell activity in children with untreated acute leukemia. Cancer Res. 43, 5580 5585.

Nguyen, S., Dhedin, N., Vernant, J. P., Kuentz, M., Al Jijakli, A., RouasFreiss, N., et al. (2005). NK-cell reconstitution after haploidentical hematopoietic stem-cell transplantations: immaturity of $\mathrm{NK}$ cells and inhibitory effect of NKG2A override GvL effect. Blood 105, 41354142.

Nowbakht, P., Ionescu, M. C., Rohner, A., Kalberer, C. P., Rossy, E., Mori, L., et al. (2005). Ligands for natural killer cell-activating receptors are expressed upon the maturation of normal myelomonocytic cells but at low levels in acute myeloid leukemias. Blood 105, 3615-3622.

Passweg, J. R., Koehl, U., Uharek, L., Meyer-Monard, S., and Tichelli, A. (2006). Natural-killer-cell-based treatment in haematopoietic stemcell transplantation. Best Pract. Res. Clin. Haematol. 19, 811-824.

Pende, D., Marcenaro, S., Falco, M., Martini, S., Bernardo, M. E., Montagna, D., et al. (2009). Anti-leukemia activity of alloreactive NK cells in KIR ligand-mismatched haploidentical HSCT for pediatric patients: evaluation of the functional role of activating KIR and redefinition of inhibitory KIR specificity. Blood 113, 3119-3129.

Pende, D., Spaggiari, G. M., Marcenaro, S., Martini, S., Rivera, P., Capobianco, A., etal. (2005). Analysis of the receptor-ligand interactions in the natural killer-mediated lysis of freshly isolated myeloid or lymphoblastic leukemias: evidence for the involvement of the Poliovirus receptor (CD155) and Nectin-2 (CD112). Blood 105, 2066-2073.

Petersdorf, E. W., Anasetti, C., Martin, P. J., Gooley, T., Radich, J., Malkki, M., et al. (2004). Limits of HLA mismatching in unrelated hematopoietic cell transplantation. Blood 104, 2976 2980.

Pfeiffer, M. M., Feuchtinger, T., Teltschik, H. M., Schumm, M. Muller, I., Handgretinger, R., et al. (2010). Reconstitution of natural killer cell receptors influences natural killer activity and relapse rate after haploidentical transplantation of $\mathrm{T}$ and B-cell depleted grafts in children. Haematologica 95, 1381-1388.

Raulet, D. H., Held, W., Correa, I. Dorfman, J. R., Wu, M. F., and Corral, L. (1997). Specificity, tolerance and developmental regulation of natural killer cells defined by expression of class I-specific Ly49 receptors. Immunol. Rev. 155, 41-52.

Raulet, D. H., Vance, R. E., and Mcmahon, C. W. (2001). Regulation of the natural killer cell receptor repertoire. Annu. Rev. Immunol. 19, 291-330.

Re, F., Staudacher, C., Zamai, L., Vecchio, V., and Bregni, M. (2006). Killer cell Ig-like receptors ligandmismatched, alloreactive natural killer cells lyse primary solid tumors. Cancer 107, 640-648.

Romagnani, C., Juelke, K., Falco, M., Morandi, B., D’Agostino, A., Costa, R., et al. (2007). CD56brightCD16 ${ }^{-}$ killer Ig-like receptor ${ }^{-} \mathrm{NK}$ cells display longer telomeres and acquire features of CD56dim NK cells upon activation. J. Immunol. 178, 49474955.

Rubnitz, J. E., Inaba, H., Ribeiro, R C., Pounds, S., Rooney, B., Bell, T., et al. (2010). NKAML: a pilot study to determine the safety and feasibility of haploidentical natural killer cell transplantation in childhood acute myeloid leukemia. J. Clin. Oncol. 28, 955-959.

Ruggeri, L., Capanni, M., Urbani, E., Perruccio, K., Shlomchik, W. D., Tosti, A., et al. (2002). Effectiveness of donor natural killer cell alloreactivity in mismatched hematopoietic transplants. Science 295, 2097-2100.

Ruggeri, L., Mancusi, A., Burchielli, E., Capanni, M., Carotti, A., Aloisi, T., et al. (2008). NK cell alloreactivity and allogeneic hematopoietic stem cell transplantation. Blood Cells $\mathrm{Mol}$. Dis. 40, 84-90.

Ruggeri, L., Mancusi, A., Capanni, M., Urbani, E., Carotti, A., Aloisi, T., et al. (2007). Donor natural killer cell allorecognition of missing self in haploidentical hematopoietic transplantation for acute myeloid leukemia: challenging its predictive value. Blood 110, 433-440.

Schonberg, K., Fischer, J. C., Kogler, G., and Uhrberg, M. (2011a). Neonatal NK-cell repertoires are functionally, but not structurally, biased toward recognition of self HLA class I. Blood 117, 5152-5156.

Schonberg, K., Sribar, M., Enczmann, J., Fischer, J. C., and Uhrberg, M. (2011b). Analyses of HLA-Cspecific KIR repertoires in donors with group A and B haplotypes suggest a ligand-instructed model of NK cell receptor acquisition. Blood 117, 98-107.

Shi, J., Tricot, G., Szmania, S., Rosen, N., Garg, T. K., Malaviarachchi, P. A., et al. (2008). Infusion of haploidentical killer immunoglobulin-like receptor ligand mismatched NK cells for relapsed myeloma in the setting of autologous stem cell transplantation. Br. J. Haematol. 143, 641-653.

Shilling, H. G., Mcqueen, K. L., Cheng, N. W., Shizuru, J. A., Negrin, R. S., and Parham, P. (2003). Reconstitution of NK cell receptor repertoire following HLA-matched hematopoietic cell transplantation. Blood 101, 3730-3740.

Singh, S. M., Yanagawa, H., Hanibuchi, M., Miki, T., Okamura, H., and Sone, S. (2000). Augmentation by interleukin-18 of MHCnonrestricted killer activity of human peripheral blood mononuclear cells in response to interleukin-12. Int. J. Immunopharmacol. 22, 35-43.

Soiffer, R. J., Weller, E., Alyea, E. P., Mauch, P., Webb, I. L., Fisher D. C., etal. (2001). CD6+ donor marrow T-cell depletion as the sole form of graft-versus-host disease prophylaxis in patients undergoing allogeneic bone marrow transplant from unrelated donors. J. Clin. Oncol. 19, 1152-1159.

Spits, H., and Di Santo, J. P. (2011). The expanding family of innate lymphoid cells: regulators and effectors of immunity and tissue remodeling. Nat. Immunol. 12, 21-27.

Steel, J. C., Waldmann, T. A., and Morris, J. C. (2012). Interleukin-15 biology and its therapeutic implications in cancer. Trends Pharmacol. Sci. 33, 35-41.

Stein, M. N., Shin, J., Gudzowaty, O., Bernstein, A. M., and Liu, J. M. (2006). Antibody-dependent cell cytotoxicity to breast cancer targets despite inhibitory KIR signaling. Anticancer Res. 26, 1759-1763.
Stringaris, K., Adams, S., Uribe, M., Eniafe, R., Wu, C. O., Savani, B. N., et al. (2010). Donor KIR Genes 2DL5A, 2DS1 and 3DS1 are associated with a reduced rate of leukemia relapse after HLA-identical sibling stem cell transplantation for acute myeloid leukemia but not other hematologic malignancies. Biol. Blood Marrow Transplant. 16, 1257-1264.

Szczepanski, M. J., Szajnik, M., Welsh, A., Foon, K. A., Whiteside, T. L., and Boyiadzis, M. (2010). Interleukin-15 enhances natural killer cell cytotoxicity in patients with acute myeloid leukemia by upregulating the activating NK cell receptors. Cancer Immunol. Immunother. 59, 73-79.

Trinchieri, G. (2003). Interleukin-12 and the regulation of innate resistance and adaptive immunity. Nat. Rev. Immunol. 3, 133-146.

Trowsdale, J., Barten, R., Haude, A., Stewart, C. A., Beck, S., and Wilson, M. J. (2001). The genomic context of natural killer receptor extended gene families. Immunol. Rev. 181, 20-38.

Uhrberg, M. (2005a). The KIR gene family: life in the fast lane of evolution. Eur. J. Immunol. 35, 10-15.

Uhrberg, M. (2005b). Shaping the human NK cell repertoire: an epigenetic glance at KIR gene regulation. Mol. Immunol. 42, 471-475.

Uhrberg, M., Parham, P., and Wernet, P. (2002). Definition of gene content for nine common group B haplotypes of the Caucasoid population: KIR haplotypes contain between seven and eleven KIR genes. Immunogenetics 54, 221-229.

Uhrberg, M., Valiante, N. M., Shum, B. P., Shilling, H. G., LienertWeidenbach, K., Corliss, B., et al. (1997). Human diversity in killer cell inhibitory receptor genes. Immunity 7, 753-763.

Vago, L., Forno, B., Sormani, M. P., Crocchiolo, R., Zino, E., Di Terlizzi, S., etal. (2008). Temporal, quantitative, and functional characteristics of single-KIRpositive alloreactive natural killer cell recovery account for impaired graftversus-leukemia activity after haploidentical hematopoietic stem cell transplantation. Blood 112, 34883499.

Vales-Gomez, M., Reyburn, H. T., Erskine, R. A., and Strominger, J. (1998). Differential binding to HLA-C of p50-activating and p58inhibitory natural killer cell receptors. Proc. Natl. Acad. Sci. U.S.A. 95, 14326-14331.

Valiante, N. M., Uhrberg, M., Shilling, H. G., Lienert-Weidenbach, K., 
Arnett, K. L., D'Andrea, A., et al. (1997). Functionally and structurally distinct NK cell receptor repertoires in the peripheral blood of two human donors. Immunity 7, 739-751.

VandenBussche, C. J., Mulrooney, T. J., Frazier, W. R., Dakshanamurthy, S., and Hurley, C. K. (2009). Dramatically reduced surface expression of NK cell receptor KIR2DS3 is attributed to multiple residues throughout the molecule. Genes Immun. 10, 162-173.

Venstrom, J. M., Pittari, G., Gooley, T. A., Chewning, J. H., Spellman, S., Haagenson, M., etal. (2012). HLAC-dependent prevention of leukemia relapse by donor activating KIR2DS1. N. Engl. J. Med. 367, 805-816.

Verheyden, S., Bernier, M., and Demanet, C. (2004). Identification of natural killer cell receptor phenotypes associated with leukemia. Leukemia 18, 2002-2007.

Verheyden, S., and Demanet, C. (2008). NK cell receptors and their ligands in leukemia. Leukemia 22, 249-257.

Vierra-Green, C., Roe, D., Hou, L., Hurley, C. K., Rajalingam, R., Reed, E., et al. (2012). Allele-level haplotype frequencies and pairwise linkage disequilibrium for $14 \mathrm{KIR}$ loci in 506 European-American individuals. PLoS ONE 7:e47491. doi: 10.1371/journal.pone.0047491

Vilches, C., and Parham, P. (2002). KIR: diverse, rapidly evolving receptors of innate and adaptive immunity. Annu. Rev. Immunol. 20, 217-251.

Waldmann, T. A. (2006). The biology of interleukin-2 and interleukin-15: implications for cancer therapy and vaccine design. Nat. Rev. Immunol. 6 , 595-601.

Winter, C. C., Gumperz, J. E. Parham, P., Long, E. O., and Wagtmann, N. (1998). Direct binding and functional transfer of NK cell inhibitory receptors reveal novel patterns of HLA-C allotype recognition. J. Immunol. 161, 571-577.

Woolfrey, A., Klein, J. P., Haagenson, M., Spellman, S., Petersdorf, E., Oudshoorn, M., etal. (2011). HLA-C antigen mismatch is associated with worse outcome in unrelated donor peripheral blood stem cell transplantation. Biol. Blood Marrow Transplant. 17, 885-892.

Yawata, M., Yawata, N., Draghi, M. Little, A. M., Partheniou, F., and Parham, P. (2006). Roles for HLA and KIR polymorphisms in natural killer cell repertoire selection and modulation of effector function. J. Exp. Med. 203, 633-645.

Yawata, M., Yawata, N., Draghi, M. Partheniou, F., Little, A. M., and Parham, P. (2008). MHC class Ispecific inhibitory receptors and their ligands structure diverse human NKcell repertoires toward a balance of missing self-response. Blood 112, 2369-2380.

Yokoyama, W. M., Kim, S., and French, A. R. (2004). The dynamic life of natural killer cells. Annu. Rev. Immunol. 22, 405-429.

Young, H. A., and Ortaldo, J. (2006) Cytokines as critical co-stimulatory molecules in modulating the immune response of natural killer cells. Cell Res. 16, 20-24.

Young, N. T., Canavez, F., Uhrberg, M., Shum, B. P., and Parham, P. (2001). Conserved organization of the ILT/LIR gene family within the polymorphic human leukocyte receptor complex. Immunogenetics 53, 270-278.

Yu, J., Heller, G., Chewning, J., Kim, S., Yokoyama, W. M., and Hsu, K. C. (2007). Hierarchy of the human natural killer cell response is determined by class and quantity of inhibitory receptors for self-HLA-B and HLAC ligands. J. Immunol. 179, 59775989.

Yu, J., Venstrom, J. M., Liu, X. R., Pring, J., Hasan, R. S., O’Reilly, R. J., etal. (2009). Breaking tolerance to self, circulating natural killer cells expressing inhibitory KIR for non-self HLA exhibit effector function after $\mathrm{T}$ cell-depleted allogeneic hematopoietic cell transplantation. Blood 113, 3875-3884.

Zhang, M., Yao, Z., Dubois, S., Ju, W., Muller, J. R., and Waldmann, T.
A. (2009). Interleukin-15 combined with an anti-CD40 antibody provides enhanced therapeutic efficacy for murine models of colon cancer. Proc. Natl. Acad. Sci. U.S.A. 106, 7513-7518.

Conflict of Interest Statement: The authors declare that the research was conducted in the absence of any commercial or financial relationships that could be construed as a potential conflict of interest.

Received: 16 November 2012; paper pending published: 04 December 2012; accepted: 23 January 2013; published online: 07 February 2013.

Citation: Babor F, Fischer JC and Uhrberg $M$ (2013) The role of KIR genes and ligands in leukemia surveillance. Front. Immun. 4:27. doi: 10.3389/ fimmu.2013.00027

This article was submitted to Frontiers in NK Cell Biology, a specialty of Frontiers in Immunology.

Copyright (c) 2013 Babor, Fischer and Uhrberg. This is an open-access article distributed under the terms of the Creative Commons Attribution License, which permits use, distribution and reproduction in other forums, provided the original authors and source are credited and subject to any copyright notices concerning any third-party graphics etc. 